\title{
ANALISIS DETERMINASI KOMPETENSI PENGELOLA DAN INTENSITAS MENGGUNAKAN LABORATORIUM TERHADAP KETERAMPILAN MENGOPERASIKAN MESIN BALANCING DITINJAU DARI BAKAT MEKANIK PADA MAHASISWA TEKNIK MESIN UNDIKSHA
}

\author{
Oleh \\ Ketut Darma Yuliawan, Nyoman Dantes, Ni Ketut Widiartini \\ Program Studi Penelitian dan Evaluasi Pendidikan \\ Program Pascasarjana Universitas Pendidikan Ganesha \\ Singaraja, Indonesia
}

Email : kojek buleleng@yahoo.com, nyoman.dantes@pasca.undiksha.ac.id, ketut.widiartini@pasca.undiksha.ac.id,

\begin{abstract}
Abstrak
Tujuan dari penelitian ini adalah untuk mengetahui seberapa besar determinasi dari kompetensi pengelola laboratorium dan intensitas siswa menggunakan laboratorium ditinjau dari bakat mekanik. Populasi dan sampel dalam penelitian ini adalah mahasiswa prodi Pendidikan Teknik Mesin Universitas Pendidikan Ganesha yang berjumlah 36 orang. Teknik pengambilan sampel yang digunakan adalah purposive sampling. Metode pengambilan data dengan menggunakan tes, kuesioner dan rubrik pengamatan.Penelitian ini adalah penelitian non eksperimen (ex-post facto). Analisis yang digunakan dalam penelitian ini adalah anava satu jalur, anakova satu jalur satu dan dua kovariabel, korelasi parsial dan multiple regresi. Hasil penelitian menunjukkan bahwa : (1) terdapat perbedaan keterampilan mengoperasikan mesin balancing antara siswa yang memiliki bakat mekanik tinggi dan rendah ; (2) terdapat perbedaan keterampilan mengoperasikan mesin balancing antara siswa yang memiliki bakat mekanik tinggi dan rendah setelah dikendalikan oleh kompetensi pengelola laboratorium maupun setelah dikendalikan oleh intensitas siswa menggunakan laboratorium; (3) terdapat determinasi dari kompetensi pengelola laboratorium dan intensitas siswa menggunakan laboratorium terhadap keterampilan siswa mengoperasikan mesin balancing.
\end{abstract}

Kata Kunci : bakat mekanik, kompetensi, intensitas,keterampilan.

\begin{abstract}
The purpose of this study is to determine how much determination of the competence of laboratory managers and the intensity of students using the laboratory in terms of mechanical talent. Population and sample in this research is student of Mechanical Engineering Education University Ganesha Education which amounts to 36 people. The sampling technique used is purposive sampling. Methods of data retrieval using test, questionnaire and rubric observation. This research is a non experimental research (expost facto). Analysis used in this research is one path anava, anakova one lane one and two kovariabel, partial correlation and multiple regresi. The results showed that: (1) there were differences in the skill of operating balancing machines between students with high and low mechanical talents; (2) there is a difference in the skill of operating balancing machines between students who have high and low mechanical talents after controlled by the competence of the laboratory managers and after being controlled by the intensity of the students using the laboratory; (3) there is determination of laboratory manager competence and student intensity using laboratory to student skill to operate balancing machine.
\end{abstract}


Key words : mechanical talent, competence, intensity,skills

\section{PENDAHULUAN}

Pendidikan yang baik adalah pendidikan yang mampu mengembangkan kemampuan serta memotivasi peserta didik untuk menggali potensi yang ada pada dirinya. Sistem Pendidikan seperti itulah yang mampu menghasilkan sumber daya manusia ( SDM ) yang mempunyai visi misi dan pandangan jauh ke depan untuk dirinya sendiri serta untuk bangsa dan negara. Harapan tentang meningkatnya kualitas pendidikan ternyata belum sesuai dengan kenyataan di lapangan. Belum optimalnya hasil belajar peserta didik dapat dipengaruhi berbagai macam faktor, salah satunya adalah proses pembelajaran di kelas.

Menurut Sanjaya (2008:26), pembelajaran adalah proses kerja sama antara guru dan siswa dalam memanfaatkan segala potensi dan sumber yang ada, baik potensi yang bersumber dari dalam diri siswa seperti minat, bakat, dan kemampuan dasar yang dimiliki, termasuk gaya belajar dan potensi yang ada di luar diri siswa seperti lingkungan, sarana, dan sumber belajar sebagai upaya untuk mencapai tujuan belajar tertentu. Dalam proses pembelajaran akan dihasilkan pengetahuan dan keterampilan yang didapat oleh siswa. Menurut teori konstruksi, keberhasilan belajar dari seorang siswa bukan hanya tergantung oleh lingkungan atau kondisi belajar melainkan juga pengetahuan awal siswa yang tidak dapat dipindahkan secara utuh langsung dari pikiran guru ke siswa, akan tetapi siswa sendirilah yang harus secara aktif membangun pengetahuan tersebut melalui pengalaman nyata (Slavin, 2011). Kenyataan yang terjadi saat ini, dalam proses pembelajaran seringkali peserta didik hanya diberikan informasi oleh pendidik berupa teori saja. Untuk mendapatkan kualitas pendidikan yang bagus dan sumber daya manusia yang kompeten, tidak cukup hanya dengan memberikan teori di depan kelas. Di era globalisasi seperti saat ini dibutuhkan SDM yang memiliki keterampilan agar mereka bisa bersaing di dunia usaha yang akan mereka geluti setelah tamat dari universitas. Keterampilan tersebut bisa mereka dapatkan dengan memberikan kesempatan kepada mereka untuk mempraktekkan teori yang sudah mereka dapatkan dari pendidik. Praktikum memberikan kesempatan kepada siswa untuk mengembangkan teori yang didapat di kelas sehingga nantinya siswa diharapkan memiliki keterampilan. Dalam bidang teknik mesin, kegiatan praktek adalah kegiatan yang sangat penting dilakukan oleh peserta didik untuk mengembangkan teori yang didapatkan di kelas dan juga agar peserta didik mempunyai keterampilan dalam bidang teknik mesin yang nantinya sebagai bekal mereka dalam dunia kerja. Salah satu keterampilan yang ada dalam bidang teknik mesin adalah kemampuan mengoperasikan mesin balancing.

Balancing adalah suatu proses yang dilakukan untuk menstabilkan putaran roda agar seimbang dan merata pada masingmasing permukaan roda (Ridho Jordan Firmansyah,2015) . Keterampilan mengoperasikan mesin balancing ini tidak bisa diperoleh hanya dengan teori yang didapat di kelas. Siswa harus melakukan praktek di lapangan. Salah satu sarana pendidikan yang berfungsi sebagai penunjang dalam pelaksanaan proses pembelajaran di universitas, terutama yang berhubungan dengan kegiatan praktikum adalah laboratorium.

Menurut Peraturan Bersama Menteri Pendidikan Nasional Nomor 02/V/PB/2010 dan Kepala Badan Kepegawaian Negara Nomor 13 tahun 2010, laboratorium pendidikan yang selanjutnya disebut laboratorium adalah unit penunjang akademik pada lembaga pendidikan, berupa ruangan tertutup atau terbuka, bersifat permanen atau bergerak, dikelola secara sistematis untuk kegiatan pengujian, kalibrasi, dan/atau produksi dalam skala terbatas, dengan menggunakan peralatan dan bahan berdasarkan metode keilmuan tertentu, dalam rangka pelaksanaan pendidikan, penelitian, dan pengabdian kepada masyarakat. Pada tingkat universitas/jurusan/program studi, laboratorium selain digunakan untuk proses pendidikan, seringkali juga digunakan untuk 
kegiatan penelitian dan pengabdian masyarakat. Di tingkat universitas, laboratorium yang ada adalah laboratorium terpadu. Laboratorium pendidikan terpadu merupakan unit pelaksana teknis di bidang pengembangan pembelajaran dan layanan laboratorium yang berada di bawah dan bertanggung jawab kepada rektor dan dikoordinasikan oleh wakil rektor bidang akademik. Laboratorium pendidikan terpadu mempunyai tugas melaksanakan layanan laboratorium untuk program pendidikan, penelitian, dan pengabdian kepada masyarakat secara terpadu. Laboratorium di tingkat jurusan/universitas dikelola secara profesional oleh pengelola laboratorium. Pengelola laboratorium bertugas sebagi administrator semua kegiatan yang berlangsung di laboratorium, baik itu kegiatan pendidikan, penelitian maupun pengabdian masyarakat. Pengelola laboratorium terdiri dari seorang laboran yang bertugas sebagi administrator kegiatan sehari- hari di laboratorium dan seorang kepala laboratorium yang bertugas sebagai koordinator kegiatan laboratorium. Agar kegiatan di laboratorium dapat berjalan dengan baik dan memberikan fungsi kepada mahasiswa, ada beberapa faktor yang menentukan keberhasilan pelaksanaan kegiatan praktikum di laboratorium. Faktor tersebut diantaranya adalah kompetensi pengelola laboratorium dan intensitas keterlibatan mahasiswa menggunakan laboratorium. Menurut Mustafah ( 2011, ), kompetensi adalah kemampuan seseorang yang meliputi pengetahuan, keterampilan, dan sikap yang dapat diwujudkan dalam hasil kerja nyata yang bermanfaat bagi diri sendiri dan lingkungannya. Kompetensi menjadi kebutuhan untuk memperoleh sumber daya yang unggul dan professional yang sangat diharapkan banyak organisasi. Dalam kaitannya dengan pelaksanaan praktikum di laboratorium, keberhasilan kegiatan laboratorium menurut Sappaile (2007:11) didukung oleh tiga faktor, yaitu peralatan, bahan dan fasilitas lainnya, tenaga laboratorium, serta bimbingan pendidik yang diperoleh peserta didik dalam melakukan tugas-tugas. Menurut Permen PAN-RB Nomor 03 Tahun 2010 tentang Jabatan Fungsional Pranata Laboratorium Pendidikan dan Angka Kreditnya, kompetensi PLP/laboran meliputi kompetensi pengetahuan,keahlian/ manajerial dan kepribadian/sikap. Kompetensi pengelola laboratorium adalah kemampuan, pengetahuan, keterampilan dan sikap yang dimiliki PLP/laboran dalam melaksanakan tugas keprofesionalannya di laboratorium. Selain kompetensi, faktor yang juga berpengaruh terhadap keberhasilan embelajaran di laboratorium adalah tingkat keseringan siswa dalam menggunakan laboratorium atau yang disebut intensitas. Menurut (Setiawati,2015), intensitas adalah adalah tingkat keseringan/frekuensi yang diperlukan. Intensitas penggunaan fasilitas pendukung belajar adalah tingkat keseringan atau frekuensi penggunaan fasilitas belajar/penunjang kegiatan belajar yang dilakukan oleh mahasiswa dalam kegiatan belajarnya. Dalam pembelajaran praktikum, seberapa sering mahasiswa dalam menggunakan laboratorium akan mempengaruhi keberhasilan belajar mahasiswa. Hal ini sesuai dengan penelitian yang dilakukan oleh Dian Eka Budi Yanti (2016). Dalam penelitiannya diungkapkan bahwa intensitas kegiatan praktikum fisika berpengaruh baik dalam mendukung pelaksanaan pembelajaran Fisika. Intensitas sangat erat kaitannya dengan motivasi karena untuk terjadinya intensitas harus didahului dengan adanya motivasi pada diri mahasiswa sendiri. Intensitas merupakan reaksi yang timbul dari motivasi dalam rangka mencapai tujuan yang diharapkan yaitu peningkatan prestasi, sebab seseorang melakukan usaha dengan penuh semangat karena adanya motivasi sebagai pendorong pencapaian prestasi. Beberapa dimensi yang dijadikan acuan dalam mengukur intensitas adalah motivasi, frekuensi, durasi serta keinginan/semangat. Selain kedua faktor diatas, salah satu faktor yang sangat menentukan keberhasilan mahasiswa terampil mengoperasikan mesin balancing adalah bakat mekanik yang dimiliki mereka sendiri. Pernyataan tersebut sesuai dengan penelitian yang dilakukan oleh Gusrial (2013 dalam Pradana, 2014). Dalam penelitiannya, Gusrial menyatakan bahwa terdapat hubungan yang positif dan signifikan antara bakat mekanik terhadap prestasi belajar produktif. Menurut Djamarah 
(2002:162), bakat adalah kemampuan bawaan yang merupakan potensi yang masih perlu dikembangkan atau dilatih. Bakat yang dimiliki seseorang harus dilatih secara terus menerus sehingga nantinya akan menghasilkan kemampuan sehingga tercipta suatu keterampilan khusus yang dimiliki orang tersebut. Bakat orang satu sama lainnya tentu akan berbeda dan beragam. Ada yang berbakat di bidang olahraga, menari, menyanyi dan sebagainya. Bakat memiliki peranan penting dalam keberhasilan seorang peserta didik pada jurusan atau kompetensi yang dipilihnya. Perkembangan bakat seseorang bisa dipengaruhi oleh beberapa faktor diantaranya tingkat pendidikan, lingkungan sekitar, motivasi, minat dan emosi. Bakat dapat dikembangkan dengan cara : (1). berani untuk memulai dan berani gagal ; (2). latihan ; (3). dukungan lingkungan ; (4). memahami hambatan dan cara mengatasi. Bakat mekanik adalah kemampuan yang dimiliki dalam diri sesorang dalam bidang permesinan yang masih harus dilatih untuk melahirkan pengetahuan, kecakapan dan keterampilan-keterampilan khusus. Beberapa ciri orang yang memiliki bakat mekanik adalah (1) kemampuan mekanik yang tergolong di atas rata-rata; (2) kreativitas yang dimiliki lebih tinggi; (3) lebih komitmen pada tugasnya.Dalam bidang permesinan, bakat mekanik adalah salah satu faktor yang sangat berpengaruh terhadap keberhasilan belajar siswa. Pernyataan ini sesuai dengan penelitian yang dilakukan oleh Penny Maryati (2012) dalam Aditya Wahyu Pradana ( 2014). Dalam penelitian tersebut dinyatakan bahwa bakat mekanik mempunyai hubungan yang positif terhadap kompetensi siswa. Artinya siswa yang mempunyai bakat mekanik tinggi maka prestasi belajar praktik pemesinannya juga tinggi.

Berdasarkan fakta di atas, beberapa faktor yang menentukan keberhasilan pembelajaran di laboratorium adalah kompetensi pengelola laboratorium, intensitas siswa menggunakan laboratorium serta bakat mekanik yang dimiliki siswa, sehingga tujuan dari penelitian ini adalah untuk mengetahui apakah terdapat perbedaan keterampilan mengoperasikan mesin balancing antara siswa yang memiliki bakat mekanik tinggi dan siswa yang memiliki bakat mekanik rendah setelah dikendalikan oleh kompetensi pengelola laboratorium dan intensitas siswa menggunakan laboratorium serta untuk mengetahui seberapa besar determinasinya.

\section{METODE}

Penelitian ini adalah penelitian non eksperimen ( ex post facto ). Penelitian ex post facto merupakan suatu pendekatan pada subjek penelitian untuk meneliti yang telah dimiliki oleh subjek penelitian secara wajar tanpa adanya usaha sengaja memberikan perlakuan untuk memunculkan variabel yang ingin diteliti ( Dantes 2012 ).

Konstelasi Variabel :

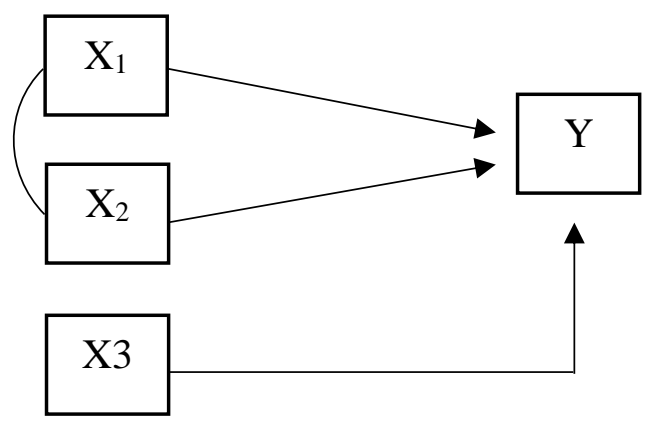

Variabel :

$\mathrm{X} 1$ : kompetensi pengelola laboratorium

X2: intensitas siswa menggunakan laboratorium

X3: bakat mekanik

$\mathrm{Y}$ : keterampilan siswa mengoperasikan mesin balancing

Populasi pada penelitian ini adalah mahasiswa semester III prodi Pendidikan Teknik Mesin Universitas Pendidikan Ganesha yang berjumlah 36 orang. Sampel yang digunakan dalam penelitian ini adalah sama dengan jumlah populasi. Karena seluruh individu yang terdapat dalam wilayah penelitian ini diteliti, maka penelitian ini disebut dengan studi sensus / cencus study. Studi sensus adalah studi/penelitian yang meneliti seluruh individu/kasus yang ada di wilayah penelitian dalam satu atau beberapa karakterisik (variabel) yang telah ditentukan terlebih dahulu oleh peneliti ( 
Dantes 2012 ). Teknik pengambilan sampel yang digunakan adalah purposive sampling karena peneliti telah menetapkan tujuan dari penetapan sampel tersebut. Tujuan yang ditetapkan oleh peneliti dari sampel yang ada adalah mendapatkan data bakat mekanik tinggi dan rendah.

Data dikumpulkan dengan menggunakan tes bakat mekanik, kuesioner serta rubrik lembar pengamatan. Data tersebut kemudian dianalisa menggunakan anava satu jalur, anakova satu jalur, analisis korelasi parsial dan multiple regresi.

\section{HASIL DAN PEMBAHASAN}

Dari proses analisis data, didapat hasil penelitian sebagai berikut :

1). Berdasarkan hasil perhitungan ANAVA A untuk hipotesis penelitian ini, tampak bahwa nilai $F$ hitung sebesar 6.79. Sedangkan nilai $F$ pada tabel dengan taraf signifikansi $5 \%$ untuk $\mathrm{dkA}=\mathrm{k}-1=1$ dan $\mathrm{dkD}=\mathrm{N}-\mathrm{k}=34$ adalah 4,17. Dengan demikian harga $F$ hitung lebih besar dari harga $F$ tabel sehingga $\mathrm{H} 1$ diterima yang artinya terdapat perbedaan keterampilan mengoperasikan mesin balancing antara siswa yang memiliki bakat mekanik tinggi dan siswa yang memiliki bakat mekanik rendah.

\begin{tabular}{|c|c|c|c|c|c|c|}
\hline SV & JK & dk & RJK & $\begin{array}{c}F \\
\text { hitung }\end{array}$ & $\begin{array}{c}F \\
\text { tabel }\end{array}$ & Ket. \\
\hline Antar & 29.43 & 1 & 29.43 & 6.79 & 4.17 & signifikan \\
\hline Dalam & 147.32 & 34 & 4.33 & & & \\
\hline & & & & & & \\
\hline Total & 176.75 & 35 & & & & \\
\hline
\end{tabular}

Bakat mekanik merupakan bakat bawaan yang sudah ada pada diri seseorang sejak orang tersebut dilahirkan. Namun bakat ini masih harus dilatih secara terus menerus agar menciptakan keterampilan yang akan dimiliki oleh orang tersebut. Selain faktor internal dari diri sendiri, faktor lain yang berpengaruh terhadap perkembangan bakat mekanik mahasiswa adalah dari lingkungan sekitar baik di lingkungan tempat tinggal, keluarga dan teman. Bakat mekanik berpengaruh terhadap keterampilan siswa dibuktikan dengan penelitian yang dilakukan oleh Suwandi ( 2010 ), yang menunjukkan bahwa bakat mekanik berpengaruh terhadap hasil belajar mengelas siswa. Semakin tinggi bakat mekanik yang dimiliki oleh siswa maka prestasi/keterampilan belajar siswa juga akan semakin tinggi. Pernyataan ini dibuktikan oleh penelitian yang dilakukan oleh Pradana ( 2014 ). Dalam penelitiannya, Pradana menunjukkan bahwa semakin tinggi bakat mekanik yang dimiliki siswa maka prestasi belajarnya akan semakin tinggi.

2). Berdasarkan hasil perhitungan Anakova satu jualur untuk hipotesis penelitian ini, tampak bahwa nilai $\mathrm{F}$ hitung sebesar 8.53. Sedangkan nilai $\mathrm{F}$ pada tabel dengan taraf signifikansi $5 \%$ untuk dkA=k-1 = 1 dan $\mathrm{dkD}=$ $\mathrm{N}-\mathrm{k}-\mathrm{M}=33$ adalah 4,17. Dengan demikian harga $F$ hitung lebih besar dari harga $F$ tabel yang artinya terdapat perbedaan keterampilan mengoperasikan mesin balancing antara siswa yang memiliki bakat mekanik tinggi dan siswa yang memiliki bakat mekanik rendah setelah dikendalikan oleh kompetensi pengelola laboratorium.

\begin{tabular}{|c|c|c|c|c|c|}
\hline SV & JK & $\mathbf{d k}$ & RJK & F hitung & F tabel \\
\hline Antar & 34.35 & 1 & 34.35318 & 8.525338 & 4.17 \\
\hline Dalam & 132.97 & 33 & 4.029539 & & \\
\hline Total & 167.33 & 34 & & & \\
\hline
\end{tabular}

Pengelola laboratorium merupakan ujung tombak berhasil tidaknya pembelajaran yang berlangsung di laboratorium. Kualitas layanan yang didapat oleh mahasiswa sangat dipengaruhi oleh seberapa tinggi kompetensi yang dimiliki oleh pengelola laboratorium yang dalam hal ini adalah laboran. Hasil yang didapat dalam penelitian ini ini sejalan dengan penelitian yang dilakukan oleh Danang Sulistyanto ( 2017 ) yang menunjukkan semakin tinggi kompetensi pengelola laboratorium makin tinggi pula kontribusinya terhadap efektivitas pembelajaran IPA. Penelitian lain yang dilakukan oleh Nirlawati dan Soeharto (2016) menunjukkan bahwa kompetensi yang dimiliki laboran berpengaruh terhadap mutu layanan yang diberikan oleh laboran. Semakin tinggi kompetensi yang dimiliki laboran semakin tinggi pula mutu layanan 
yang diberikan laboran terhadap siswa sehingga kinerja siswa dalam melakukan praktek pembelajaran di laboratorium semakin tinggi pula.

3). Berdasarkan hasil perhitungan Anakova satu jualur untuk hipotesis penelitian ini, tampak bahwa nilai $\mathrm{F}$ hitung sebesar 6.171. Sedangkan nilai $F$ pada tabel dengan taraf signifikansi $5 \%$ untuk dkA $=\mathrm{k}-1=1 \mathrm{dan} \mathrm{dkD}=$ $\mathrm{N}-\mathrm{k}-\mathrm{M}=33$ adalah 4,17. Dengan demikian harga $F$ hitung lebih besar dari harga $F$ tabel yang artinya terdapat perbedaan keterampilan mengoperasikan mesin balancing antara siswa yang memiliki bakat mekanik tinggi dan siswa yang memiliki bakat mekanik rendah setelah dikendalikan oleh intensitas siswa menggunakan laboratorium.

\begin{tabular}{|c|c|c|c|c|c|}
\hline SV & JK & DK & RJK & F hitung & F tabel \\
\hline Antar & 29.0035 & 1 & 29.0035 & 6.497141 & 4.17 \\
\hline Dalam & 147.3133 & 33 & 4.46404 & & \\
\hline Total & 176.3168 & 34 & & & \\
\hline
\end{tabular}

Dalam bidang teknik, teori yang dimiliki tidak akan berarti apabila tidak dibarengi dengan praktek. Mereka akan mempraktekkan teori yang dimiliki secara periodik sehingga mereka memiliki pengalaman yang seiring dengan berjalannya waktu mereka akan memiliki keahlian dan keterampilan dalam bidang tersebut. Mahasiswa yang rajin berkunjung ke laboratorium untuk mempelajari peralatan yang ada akan memiliki keterampilan dibandingkan dengan mahasiswa yang hanya mempelajari peralatan tersebut melalui teori di buku tanpa mempraktekkan langsung di lapangan. Apabila mereka diberikan suatu permasalahan, mahasiswa yang intensitas menggunakan laboratorium tinggi akan sangat cepat menyelesaikan permasalahan tersebut. Hasil yang didapat pada penelitian ini sejalan dengan penelitian yang dilakukan oleh Sundoro Katili (2013) yang menunjukkan bahwa semakin tinggi intensitas penggunaan laboratorium maka semakin tinggi pula hasil pembelajaran laboratorium siswa. Hasil penelitian ini dikuatkan dengan penelitian yang dilakukan oleh Nuada dan Harahap ( 2015 ) yang menunjukkan semakin tinggi intensitas penggunaan laboratorium maka semakin tinggi pula keberhasilan pembelajaran laboratorium siswa.

4). Berdasarkan hasil perhitungan anakova satu jualur dua kovariabel untuk hipotesis penelitian ini, tampak bahwa nilai $F$ hitung sebesar 8.42. Sedangkan nilai $F$ pada tabel dengan taraf signifikansi 5\% untuk dkA=k-1 $=1$ dan $\mathrm{dkD}=\mathrm{N}-\mathrm{k}-\mathrm{M}=32$ adalah 4,17. Dengan demikian harga $F$ hitung lebih besar dari harga $F$ tabel yang artinya terdapat perbedaan keterampilan mengoperasikan mesin balancing antara siswa yang memiliki bakat mekanik tinggi dan siswa yang memiliki bakat mekanik rendah setelah dikendalikan oleh kompetensi pengelola laboratorium dan intensitas siswa menggunakan laboratorium.

\begin{tabular}{|c|c|c|c|c|c|}
\hline SV & JK & $\mathbf{d k}$ & RJK & F hitung & F tabel \\
\hline Antar & 34.46381 & 1 & 34.46381 & 8.423909 & 4.17 \\
\hline Dalam & 130.9181 & 32 & 4.09119 & & \\
\hline Total & 8.75 & 33 & & & \\
\hline
\end{tabular}

5). Dari hasil perhitungan korelasi antar variabel didapat nilai $r 12$ sebesar -0.373 , ry1 sebesar 0.231 dan ry2 sebesar 0,011 . Dari nilai tersebut didapatkan nilai koefisien korelasi parsial ry1.2 sebesar 0,2534. Kemudian didapat nilai determinasinya sebesar $(0,2534)^{2}=0,0642$ atau 6,42 \%. Dari nilai tersebut dapat disimpulkan bahwa terdapat determinasi kompetensi pengelola laboratorium sebesar $6.42 \%$ terhadap keterampilan siswa mengoperasikan mesin balancing setelah dikendalikan oleh intensitas siswa menggunakan laboratorium. 6). Dari hasil perhitungan korelasi antar variabel didapat nilai $r 12$ sebesar -0.373 , ry1 sebesar 0.231 dan ry2 sebesar 0,011 . Dari nilai tersebut didapatkan nilai koefisien korelasi parsial ry2.1 sebesar 0,1 . Kemudian didapat nilai determinasinya sebesar $(0.1)^{2}=0,01$ atau $1 \%$. Dari nilai tersebut dapat disimpulkan bahwa terdapat determinasi intensitas siswa menggunakan 
laboratorium sebesar $1 \%$ terhadap keterampilan siswa mengoperasikan mesin balancing setelah dikendalikan oleh kompetensi pengelola laboratorium. 7). Berdasarkan hasil perhitungan analisis regresi ganda untuk hipotesis penelitian ini, tampak bahwa nilai b1 sebesar 0,0628 dan b2 sebesar 0,026. Dari perhitungan juga didapat nilai JK reg.tot sebesar 11.368, nilai sumbangan relatif $\quad S R \times 1$ sebesar 0.98 ( $98 \%$ ), nilai sumbangan relatif SR $x_{2}$ sebesar $0.02(2 \%)$, nilai koefisien determinasi $R_{y}{ }^{2}$ sebesar 0.0643 ( $6.43 \%)$. Kemudian didapat nilai sumbangan efektif SE\% $x 1$ sebesar $6.3 \%$ dan SE\% x2 sebesar $0.13 \%$. Dari nilai tersebut dapat disimpulkan bahwa terdapat determinasi kompetensi pengelola laboratorium sebesar $6.3 \%$ terhadap keterampilan siswa mengoperasikan mesin balancing dan determinasi intensitas menggunakan laboratorium sebesar $0.13 \%$ terhadap keterampilan siswa mengoperasikan mesin balancing.

\section{SIMPULAN DAN SARAN}

Berdasarkan atas analisis data yang telah dilakukan, diperoleh simpulan sebagai berikut :

1. Terdapat perbedaan keterampilan mengoperasikan mesin balancing antara siswa yang memiliki bakat mekanik tinggi dan siswa yang memiliki bakat mekanik rendah.

2. Terdapat perbedaan keterampilan mengoperasikan mesin balancing antara siswa yang memiliki bakat mekanik tinggi dan siswa yang memiliki bakat mekanik rendah setelah kompetensi pengelola laboratorium dikendalikan.

3. Terdapat perbedaan keterampilan mengoperasikan mesin balancing antara siswa yang memiliki bakat mekanik tinggi dan siswa yang memiliki bakat mekanik rendah setelah intensitas siswa menggunakan laboratorium dikendalikan.

4. Terdapat perbedaan keterampilan mengoperasikan mesin balancing antara siswa yang memiliki bakat mekanik tinggi dan siswa yang memiliki bakat mekanik rendah setelah kompetensi pengelola laboratorium dan intensitas siswa menggunakan laboratorium dikendalikan.

5. Terdapat determinasi dari kompetensi pengelola laboratorium terhadap keterampilan siswa mengoperasikan mesin balancing setelah intensitas siswa menggunakan laboratorium dikendalikan sebesar $6.42 \%$.

6. Terdapat determinasi dari intensitas siswa menggunakan laboratorium terhadap keterampilan siswa mengoperasikan mesin balancing setelah kompetensi pengelola laboratorium dikendalikan sebesar $1 \%$.

7. Terdapat determinasi dari kompetensi pengelola laboratorium dan intensitas siswa menggunakan laboratorium terhadap keterampilan siswa mengoperasikan mesin balancing sebesar $6.43 \%$

Berdasarkan dari simpulan yang telah dibahas di atas, beberapa saran yang penulis berikan adalah :

1. Dalam melakukan proses pembelajaran yang berkaitan dengan permesinan, pihak sekolah/universitas hendaknya harus mengetahui terlebih dahulu bakat mekanik yang dimiliki oleh siswa. Bakat mekanik penting diketahui agar pendidik bisa memberikan bimbingan yang lebih intensif kepada siswa yang memiliki bakat mekanik rendah sehingga keterampilan yang diperoleh siswa tersebut sama nantinya bisa sama dengan siswa yang memiliki bakat mekanik tinggi.

2. Selain bakat mekanik, yang harus dipertimbangkan agar tujuan pembelajaran di laboratorium tercapai adalah kompetensi pengelola laboratorium dan intensitas siswa menggunakan laboratorium. Agar kompetensi pengelola laboratorium terus meningkat sebaiknya laboran secara berkala diikutkan dalam pelatihan-pelatihan yang berhubungan dengan tugas dan fungsi dari laboran tersebut yang diselenggarakan oleh lembaga yang berwenang. Selain hal tersebut, siswa harus diberikan keleluasaan dalam menggunakan laboratorium untuk lebih meningkatkan keterampilan siswa yang tentunya harus mematuhi aturan yang berlaku di laboratorium.

\section{DAFTAR PUSTAKA}

Athtaariq dkk. Kompetensi Dosen Terhadap Kinerja Dosen di Universitas Trunojoyo Madura. Jurnal Studi Manajemen Dan Bisnis Vol 1 No. 1 Tahun 2014 
Astuti,Puji dkk. Pengembangan Instrumen Penilaian Unjuk Kerja Praktik Perawatan Kulit Wajah Berbasis Kompetensi Di Universitas Negeri Semarang. Journal of Educational Research and Evaluation 4 (2) (2015)

Dantes, Nyoman. 2012. Metode Penelitian. Yogyakarta : CV. Andi Offset

landesi,Andarwati. Citra Diri Ditinjau Dari Intensitas Penggunaan Media Jejaring Sosial Instagram Pada Siswa Kelas Xi Sma N 9 Yogyakarta. E-Jurnal Bimbingan dan Konseling Edisi 3 Tahun Ke-5 2016

Jordan,Firmansyah,Ridho.

Spooring Balancing

http://www.academia.edu/11003167/S pooring and Balancing . Diunduh tanggal 23 November 2017

Koyan, Wayan. 2012. Statistik Pendidikan. Singaraja : Undiksha Press

Katili dkk. Analisis Sarana dan Intensitas Penggunaan Laboratorium Fisika Serta Kontribusinya Terhadap Hasil Belajar Siswa SMA Negeri di Kabupaten Jembrana. e-Journal Program Pascasarjana Universitas Pendidikan Ganesha Program Studi IPA. Volume 3 Tahun 2013

Murjoko. Pengaruh Bakat Mekanik, Tingkat Pemahaman Teori Pemesinan Dan Prestasi Praktik Pemesinan Terhadap Kesiapan Kerja. Jurnal Pendidikan Vokasional Teknik Mesin. Volume 4, Nomor 8, Tahun 2016

Mahardana,Alit Putra. 2013. Pengaruh Model Pembelajaran Sains Teknologi Masyarakat ( STM ) Berbasis Assesmen Kinerja Terhadap Hasil belajar Sistem Bahan Bakar Ditinjau Dari Kemampuan Mekanik Siswa ( Tesis ). Singaraja. Universitas Pendidikan Ganesha

Nuada dan Harahap. Analisis Sarana dan Intensitas Penggunaan Laboratorium Terhadap Keterampilan Proses Sains Siswa SMA Negeri Se-Kota Tanjungbalai. Jurnal Tabularasa Pps Unimed. Vol.12 No.1, April 2015

Peraturan Bersama Menteri Pendidikan Nasional Nomor 02/V/PB/2010 dan Kepala Badan Kepegawaian Negara Nomor 13 tahun 2010 tentang Juklak
Jabatan Fungsional. 2010. Jakarta: Mendiknas dan BKN

Pradana, Aditya Wahyu. Kesiapan Kerja Siswa Teknik Pemesinan Ditinjau Dari Bakat Mekanik Dan Prestasi Belajar. E-Jurnal Pendidikan Teknik Mesin Volume 2, Nomor 3, Tahun 2014

Peraturan Menteri Pendidikan Nasional Republik Indonesia Nomor 26 tahun 2008 tentang Standar Tenaga Laboratorium

Sekolah/Madrasah.2008. Jakarta: Kementerian Pendidikan Nasional

Peraturan Menteri pendidikan dan Kebudayaan nomor 65 tahun 2013 tentang Standar Proses Pendidikan Dasar dan

Menengah.2013.Jakarta.Kementerian Pendidikan dan Kebudayaan

Setiawati,Nur Amega. 2015. Pengaruh Sikap Dan Intensitas Penggunaan Fasilitas Pendukung Belajar Terhadap Hasil Belajar Mata Kuliah Laboratorium Akuntansi, , Research and Development Journal Of Education. Vol. 1 No. 2 April 2015

Yanti,Dian Eka Budi dkk. Analisis Sarana Prasarana Laboratorium Fisika Dan Intensitas Kegiatan Praktikum Fisika DalamMendukung Pelaksanaan Pembelajaran Fisika Sma Negeri Di KabupatenJember. Jurnal Pembelajaran Fisika, Vol. 5 No. 1, Juni 2016, hal 41-46 